IZA DP No. 952

The Neighbourhood Is Not What It Used to Be

Oddbjørn Raaum

Kjell G. Salvanes

Erik Ø. Sørensen

December 2003 


\title{
The Neighbourhood Is Not What It Used to Be
}

\author{
Oddbjørn Raaum \\ Ragnar Frisch Centre for Economic Research \\ Kjell G. Salvanes \\ Norwegian School of Economics and Business Administration \\ and IZA Bonn \\ Erik Ø. Sørensen \\ Norwegian School of Economics and Business Administration
}

Discussion Paper No. 952
December 2003

IZA

P.O. Box 7240

D-53072 Bonn

Germany

Tel.: +49-228-3894-0

Fax: +49-228-3894-210

Email: iza@iza.org

This Discussion Paper is issued within the framework of IZA's research area Welfare State and Labor Market. Any opinions expressed here are those of the author(s) and not those of the institute. Research disseminated by IZA may include views on policy, but the institute itself takes no institutional policy positions.

The Institute for the Study of Labor (IZA) in Bonn is a local and virtual international research center and a place of communication between science, politics and business. IZA is an independent, nonprofit limited liability company (Gesellschaft mit beschränkter Haftung) supported by Deutsche Post World Net. The center is associated with the University of Bonn and offers a stimulating research environment through its research networks, research support, and visitors and doctoral programs. IZA engages in (i) original and internationally competitive research in all fields of labor economics, (ii) development of policy concepts, and (iii) dissemination of research results and concepts to the interested public. The current research program deals with (1) mobility and flexibility of labor, (2) internationalization of labor markets, (3) welfare state and labor market, (4) labor markets in transition countries, (5) the future of labor, (6) evaluation of labor market policies and projects and (7) general labor economics.

IZA Discussion Papers often represent preliminary work and are circulated to encourage discussion. Citation of such a paper should account for its provisional character. A revised version may be available on the IZA website (www.iza.org) or directly from the author. 
IZA Discussion Paper No. 952

December 2003

\section{ABSTRACT}

\section{The Neighbourhood Is Not What It Used to $\mathrm{Be}^{*}$}

Using a variance decomposition framework which provides bounds on the effect of families and neighbourhoods, we find important effects of family characteristics and residential location on educational attainment and adult earnings in Norway. Neighbourhoods are less important than families, as the correlations among siblings are significantly higher than among children growing up in the same local community. The impact of neighbourhoods is reduced by half from 1960 to 1970 and we link this result to several policy changes in the 1960s aimed at increasing equality of opportunity in Norway. Neighbour correlations in Norway are found to be significantly lower than in the United States.

JEL Classification: I21, J13, R23

Keywords: education, earnings, neighbours, families, peer-effects

Corresponding author:

Kjell G. Salvanes

Department of Economics

Norwegian School of Economics and Business Administration

Helleveien 30

5045 Bergen

Norway

Email: kjell.salvanes@nhh.no

\footnotetext{
* We are grateful for comments from seminar participants at the Norwegian School of Economics, the University of Bergen, the University of Oslo, the University of Uppsala, Queen's University, the Third Norwegian Meeting in Labour Economics, ESPE2001 and EALE2002. Financial support was provided by the Norwegian Research Council, grant 120652/520 under the programme "Competence, Education and Value Creation", under the "Programme on Welfare Research", grants 140127/330 and 137236/530, and the "Programme on Efficiency in the Public Sector", grant 125251/520.
} 


\section{Introduction}

The role of families in determining socio-economic outcomes has been extensively discussed in economics as well as from other scientific perspectives. Parents influence their children via several channels: investment in their children's education, transmission of cultural values and social skills, and genetic endowments. Most studies show a strong degree of intergenerational transmission, since parental characteristics such as income and education are highly correlated with the outcomes of children along the same dimensions (Solon 1999). Geographical location of the family is one specific aspect of parental behaviour. The close link between family and neighbourhood means that the impact of the two ought to be studied together. Since families self-select into neighbourhoods, resemblance in adult outcomes among childhood neighbours may reflect family rather than neighbourhood effects. But sibling resemblance can also be due to neighbourhood effects, since most brothers and sisters grow up in the same community. An unique Norwegian dataset provides the opportunity of an integrated and historical approach, and we quantify the relative effects of families and neighbourhoods. We are also able to examine their stability over time.

Neighbourhood effects is a label for a variety of different mechanisms. Some studies have focused on social interaction in peer-groups, through attitudes and preference formation as well as the existence and enforcement of social norms (Durlauf 2001). Of course, neighbourhoods can also be important because of varying local resource bases, through availability of institutions such as schools and childcare. The significance of childhood location depends on whether these characteristics have any real impact and how they vary across neighbourhoods. Peer effects are likely to be amplified via sorting of advantaged families into advantaged neighbourhoods. The variation in local institutions such as schools and nurseries may also increase when sorting intensifies, and this would tend to reinforce peer effects.

The literature does not provide much evidence of neighbourhood effects on adult outcomes, and we know little about whether these effects are stable over time. The willingness of parents to pay a premium on house prices in order to get access to better schools and neighbourhood for their children shows that residential location is perceived as important (Black 1999; Gibbons and Machin 2002). Jargowsky (1996) finds some evidence of increased segregation by income in US 
metropolitan areas between 1970 and 1990. ${ }^{1}$ However, the evidence supporting causal effects of childhood neighbourhood characteristics on opportunities or behaviour affecting adult outcomes is far from compelling, and identification is difficult. For instance, if we think of peer group influence as one potentially important channel of residential neighbourhood effects, it is hard to distinguish the selection into neighbourhoods from the impact of peer group behaviour on individual outcomes via social interaction. Most studies report unstable and small effects of community characteristics when these are included directly into the estimation equations of adult earnings or educational attainment (Ginther, Haveman, and Wolfe 2000). In addition to high correlation between family and neighbourhood characteristics due to sorting, it is also difficult to determine which characteristics to include and what biases result from using an incomplete set of characteristics.

In light of the difficulties of estimating causal effects of neighbourhood characteristics and previous failed attempts to disentangle them from family effects, we focus on the resemblance in adult earnings and educational attainment among siblings and neighbouring children (following Solon, Page, and Duncan 2000; Page and Solon 2003). ${ }^{2}$ If aspects of the family and/or residential community during childhood and adolescence are important determinants of adult outcomes, there will be a strong correlation between siblings as compared to two arbitrarily chosen individuals. It is possible to use this correlation to bound the share of neighbourhood effects in the total variance of outcomes.

In the present paper we focus on the effects of family background and childhood location on adult educational attainment and earnings. Rich data on the full population of Norwegian citizens enable us to construct neighbourhoods and families at the time of the 1960 and 1970 censuses, and to measure adult outcomes in 1990-1995. We address the following questions: What proportions of the variation in adult socio-economic outcomes, such as education and earnings, can be explained by family and childhood neighbourhood characteristics? Are

\footnotetext{
${ }^{1}$ Kremer (1997) is sceptical to suggestions that changes in residential sorting will have a large impact on inequality in education and earnings. However, Kremer uses US census tracts as neighbourhoods, and these tracts are quite large. This may be one reason why he finds small effects of neighbourhood sorting.

${ }^{2}$ See Edin, Fredriksson, and Åslund (2003); Katz, Kling, and Liebman (2001); Oreopoulos (2003) for interesting attempts to use social experiment designs as an alternative to using data representative for a complete economy.
} 
families more important than neighbourhoods? Are these relationships stable over time?

Our combined study of siblings and neighbouring children enables us to tell the extent to which Norwegian siblings' correlations reflect childhood location rather than common endowments or family environment. By comparing our estimates with those found in US data, we can also indicate whether these relationships are similar under different institutional setting. ${ }^{3}$ Whether families and neighbourhoods have become more or less important determinants of adult outcomes is particularly interesting in light of the economic policies in Norway during the 1960s that aimed at increasing the equality of opportunity. The social reforms that took place in the 1960s which may have influenced the effect of neighbourhoods include school reforms, increased access to student grants, and a radical redistribution of resources across municipalities.

The paper is organised as follows. In the next section we describe the statistical approach used to measure the effects of family and neighbourhood on adult education attainment and earnings. Section 3 contains a data description as well as a description of the estimation procedures. The results are presented and discussed in Section 4, and Section 5 contains concluding remarks.

\section{Statistical Model}

Let $y_{c f s}$ be an outcome variable, such as permanent income or years of education, for sibling $s$ in the $f$ th family in neighbourhood $c$. We assume that we can decompose additively the role of neighbourhood, family and individual-specific factors on the outcome as

$$
y_{c f s}=\beta^{\prime} Z_{c}+\alpha^{\prime} X_{c f}+\epsilon_{c f s}
$$

where $X_{c f}$ is a vector of all family characteristics that influence permanent earnings or years of education, $Z_{c}$ contains all the neighbourhood characteristics, and

\footnotetext{
${ }^{3}$ Studies from the United States seem to dominate the existing evidence of family characteristics on adult outcomes, and especially the effect of community background has almost exclusively been studied within the US context. However, Ermisch and Francesconi (2001) and Dearden, Machin, and Reed (1997) use data for the United Kingdom to study the effect of family background. Gibbons $(2002,2003)$ finds support for neighbourhood effects on educational attainment above family effects using UK data for 1970.
} 
$\epsilon_{c f s}$ represents individual factors orthogonal to both family and neighbourhood effects. Since $Z_{c}$ and $X_{c f}$ are latent vectors that include all relevant variables, it is not a restriction to let $\epsilon_{c f s}$ be orthogonal to the explanatory variables. We expect the family background effects, $\alpha^{\prime} X_{c f}$, and the neighbourhood effects, $\beta^{\prime} Z_{c}$, to be positively correlated. Advantaged families tend to sort into advantaged neighbourhoods and children in less favourable local communities tend to have parents with fewer resources.

We are looking for the relative influence of family and neighbourhoods on adult outcomes, $\operatorname{var}\left(\alpha^{\prime} X\right) / \operatorname{var}(y)$ and $\operatorname{var}\left(\beta^{\prime} Z\right) / \operatorname{var}(y)$. The relative variance of the neighbourhood effects, $\operatorname{var}\left(\beta^{\prime} Z_{c}\right) / \operatorname{var}\left(y_{c f s}\right)$, measures the proportion of the variation in years of education or long-term earnings that can be attributed to factors shared by children from the same neighbourhood. Obviously, the correlation in adult outcomes between children growing up in the same local community cannot tell why neighbourhoods matter. They include the joint effects of variation in neighbourhood characteristics ( $Z$ 's) and the causal impact they have on adult outcomes ( $\beta$ 's).

If all the family and neighbourhood factors were observable and could be measured with accuracy, the strategy would be to estimate a regression model based on (1). Obviously, not all variables are observable or possible to measure with accuracy. Rather than arbitrarily choosing family and neighbourhood factors to include among those available, it is possible to bound the variance of neighbourhood effects by measuring neighbour covariances in $y_{c f s}$ and observed family characteristics (Solon et al. 2000). The total variance of the socioeconomic outcome, $y_{c f s}$, of all the individuals in the sample can be decomposed as

$$
\operatorname{var}\left(y_{c f s}\right)=\operatorname{var}\left(\beta^{\prime} Z_{c}\right)+\operatorname{var}\left(\alpha^{\prime} X_{c f}\right)+2 \operatorname{cov}\left(\alpha^{\prime} X_{c f}, \beta^{\prime} Z_{c}\right)+\operatorname{var}\left(\epsilon_{c f s}\right) .
$$

The covariance between neighbouring children $s$ and $s^{\prime}$ from families $f$ and $f^{\prime}$ is

$$
\operatorname{cov}\left(y_{c f s}, y_{c f^{\prime} s^{\prime}}\right)=\operatorname{var}\left(\beta^{\prime} Z_{c}\right)+\operatorname{cov}\left(\alpha^{\prime} X_{c f}, \alpha^{\prime} X_{c f^{\prime}}\right)+2 \operatorname{cov}\left(\alpha^{\prime} X_{c f}, \beta^{\prime} Z_{c}\right)
$$

In (3), we notice that the neighbour covariance consists of more than the variance in neighbourhood characteristics given in the first term. The second term, $\operatorname{cov}\left(\alpha^{\prime} X_{c f}, \alpha^{\prime} X_{c f^{\prime}}\right)$ represents sorting of similar families into the same areas, 
since neighbouring children come from similar families. We will assume that this covariance is positive. The third term, $\operatorname{cov}\left(\alpha^{\prime} X_{c f}, \beta^{\prime} Z_{c}\right)$, also represents sorting, in that it denotes the tendency of advantaged families to sort into advantaged neighbourhoods. We will assume that this also is positive. We see that these two assumptions of positive sorting, together with the linear additive form of (1), imply that $\operatorname{var}\left(\beta^{\prime} Z_{c}\right) \leq \operatorname{cov}\left(y_{c f s}, y_{c f^{\prime} s^{\prime}}\right)$. The empirical neighbour covariance can therefore be interpreted as an upper bound on the variance of neighbourhood effects.

Children from the same family share both the neighbourhood and the family background,

$$
\operatorname{cov}\left(y_{c f s}, y_{c f s^{\prime}}\right)=\operatorname{var}\left(\beta^{\prime} Z_{c}\right)+\operatorname{var}\left(\alpha^{\prime} X_{c f}\right)+2 \operatorname{cov}\left(\alpha^{\prime} X_{c f}, \beta^{\prime} Z_{c}\right)
$$

With the assumptions as outlined above, the empirical sibling covariance is also an upper bound for family effects, since the covariance includes neighbourhood characteristics such as the quality and availability of community institutions and the characteristics of the other adults and children living in the neighbourhood.

Access to neighbourhood identifiers and family characteristics in the same data enables us to tighten the bounds mentioned above, both on the neighbourhood effect and on the family effects. It follows from (3) that the upper bound on the neighbourhood effects can be made tighter by introducing observed family characteristics shared by the neighbours. Let $\tilde{X}_{c f}$ denote such an observed subset of family characteristics. Following Solon et al. (2000) and Altonji (1988), we estimate a regression of the outcome variable on $\tilde{X}_{c f}$, including a full set of neighbourhood dummy variables which will absorb the neighbourhood effects and the neighbourhood means of unobserved family characteristics. Let these within-neighbourhood estimates be denoted $\widehat{a}$. We expect the contribution from unobserved family characteristics to be positively correlated with our observed measure. Since we measure our family characteristics with error, and we cannot expect to fully proxy unobservables with observables, it seems reasonable to assume that $\operatorname{cov}\left(\widehat{a}^{\prime} \tilde{X}_{c f}, \widehat{a}^{\prime} \tilde{X}_{c f^{\prime}}\right) \leq \operatorname{cov}\left(\alpha^{\prime} X_{c f}, \alpha^{\prime} X_{c f^{\prime}}\right)$. Our preferred measure is adjusted for observed family characteristics. We use an estimated neighbour covariance and subtract the covariance in predicted family effects,

$$
\widehat{\operatorname{cov}}_{a d j} .\left(y_{c f s}, y_{c f^{\prime} s^{\prime}}\right)=\widehat{\operatorname{cov}}\left(y_{c f s}, y_{c f^{\prime} s^{\prime}}\right)-\operatorname{cov}\left(\widehat{a}^{\prime} \tilde{X}_{c f}, \widehat{a}^{\prime} \tilde{X}_{c f^{\prime}}\right)
$$


Our assumptions on the positive sorting then implies that this measure is a tighter bound on the neighbourhood effects.

Even if all the relevant family characteristics were included in $\tilde{X}_{c f}$, and the associated parameter estimates were unbiased, the adjusted covariance would still be an upper bound since the covariance between the family effects and the neighbourhood effects is not accounted for. The linear additive form of (1) is an identifying assumption for the interpretation of the $\widehat{\operatorname{cov}}_{a d j}\left(y_{c f s}, y_{c f^{\prime} s^{\prime}}\right)$ as an upper bound, as it restricts the potential for interaction between family and neighbourhoods.

Any upper bound on the variance of neighbourhood effects can be used to find a corresponding lower bound on the variance of family effects. By subtracting the adjusted neighbour covariance from the sibling correlation, what is left represents a lower bound on the variance of the family effects. The variance of the family effects can be written as

$$
\operatorname{var}\left(\alpha^{\prime} X_{c f}\right)=\operatorname{cov}\left(y_{c f s}, y_{c f s^{\prime}}\right)-\left[\operatorname{cov}\left(y_{c f s}, y_{c f^{\prime} s^{\prime}}\right)-\operatorname{cov}\left(\alpha^{\prime} X_{c f}, \alpha^{\prime} X_{c f^{\prime}}\right)\right]
$$

and we can use the fact that (5) is an upper bound on the two terms in brackets, and use $\widehat{\operatorname{cov}}\left(y_{c f s}, y_{c f s^{\prime}}\right)-\widehat{\operatorname{cov}}_{a d j} .\left(y_{c f s}, y_{c f^{\prime} s^{\prime}}\right)$ as a lower bound on the family effects. The lower bound property arise from the fact that we cannot fully observe and correct for the tendency of similar families to cluster in the same neighbourhood, the covariance between the neighbourhood and the family effects, $\operatorname{cov}\left(\alpha^{\prime} X_{c f}, \beta^{\prime} Z_{c}\right)$, does not influence the interpretation, since is included in both the neighbour and the family covariance.

\section{Data and estimation}

The database we use has been put together with sources from Statistics Norway (Møen, Salvanes, and Sørensen 2003). It includes linked administrative data, which covers all people resident in Norway. We also have the national censuses of 1960 and 1970 (Vassenden 1987). We can link records from these datasets using an unique personal identifier given to all Norwegian residents by the national population register. We use a set of household and census tract identifiers in the census to identify families and place of residence during childhood. The administrative data provide information about taxable income (excluding capital gains) 
and educational attainment, while we can use a variety of family background variables from the censuses.

\subsection{Neighbourhoods}

We use individual's recorded census tract at the time of the census as identifier of neighbourhood. Byfuglien and Langen (1983) document the principles used for delineating tract boundaries. In 1960 the main principles were that a "densely populated area" with an expected population of at least 200 persons should be a separate tract, that tract boundaries should not cross parish boundaries, nor should they cross older administrative boundaries or boundaries that would result from expected adjustments of municipalities. Where population growth was expected, tracts should be planned such that adjustments of tracts in the following census would involve only a limited number of boundary adjustments. Finally, a tract should be homogeneous with respect to communications, industry and demographical structure. These regulations were not imposed on urban municipalities in 1960, and the size of urban tracts varies considerably in the 1960 census.

In 1970 the boundaries were redrawn to reflect changes in population density and a large number of municipality mergers during the 1960's. In 1960 the 732 municipalities had a total number of 7996 tracts, while in 1970 the 451 municipalities had 8818 tracts. The average tract populations were 464 and 439 in 1960 and 1970 respectively. In 1960, 6127 tracts had a population of fewer than 500 individuals. This number grew to 6809 in $1970 .{ }^{4}$ Most of the new tracts appeared in urban areas, reflecting both urbanisation and that the formal guidelines for tract delineation only gradually were applied to urban areas. The tracts in Oslo, the capital city, had an average of 4903 inhabitants in the 1960 census; this was reduced to 1091 in 1970 as the guidelines were applied.

The Norwegian tracts were small by the international standards of the day. Sweden had 2568 "parishes" in 1971, with an average of 3145 individuals, Denmark had about 5000 primary units in 1970, with an average of 990 individuals. Great Britain had "enumeration districts" of about 750-1000 individuals, in the 1961 census (Langen 1975, p. 5-6). The US Bureau of the Census requires that the average population of all census tracts in a county be about 4000 people,

\footnotetext{
${ }^{4}$ Langen (1975), Table 4.6 and and Table 4.7.
} 
and there were 62,276 tracts and Block Numbering Areas in the US 1990 census (Bureau of the Census 1994, p. 10-1). The Norwegian census tracts are much closer in size to the US "Block Groups", a subdivision of census tracts and block numbering areas.

The neighbourhood definitions used by Solon et al. (2000) are not census subdivisions. They use data from the Panel Study of Income Dynamics, and what makes it possible to identify neighbourhoods in the PSID is a strict hierarchical sampling procedure. Within each Primary Sampling Unit, smaller areas were chosen, such as "cities, towns, census tracts, etc." (Solon et al. 2000, p. 385). At least one "chunk" of 20-30 contiguous dwellings was chosen from within each of these smaller areas, a total of 6-20 chunks per PSU. Within these chunks, 4 dwelling units were selected. From the information available, it seems reasonable to conclude that our neighbourhoods are somewhat larger than the neighbourhoods that can be identified from the PSID data, but smaller than the census tracts mostly used to assess neighbourhood effects using US data. ${ }^{5}$

We observe the neighbourhood children live in at one point in time. This may not accurately represent the environment of children from families who move about. Such measurement error will bias estimates of neighbourhood effects downward; however, families with children tend to move to neighbourhoods that are similar to those they leave, so we cannot conclude anything about the magnitude of this effect from statistics about the frequency of moving alone. One way to examine whether such moving introduces large biases is to compare the effects of 1960 neighbourhood on those who stayed to those who moved, and in Section 4.4 we examine this using a somewhat restricted and truncated sample that is different from our main sample: Because the tracts are not directly comparable across the two censuses, we construct aggregations of tracts that are comparable. Langen (appendix D, 1975) provides a catalogue of 5298 such comparable units. In many circumstances there were no changes made to tract boundaries, and the "aggregation" consists of a single tract. But some of Langen's tract aggregations are very large, the largest being Oslo, the capital, in which the tracts were completely redrawn. ${ }^{6}$ In order to examine how stable neighbourhood effects are,

\footnotetext{
${ }^{5}$ Studies such as Kremer (1997), Topa (2001) and Conley and Topa (2002) are examples using US census tracts as local neighbourhoods, but in different frameworks than ours. Solon et al. (2000, footnote 9) note that the average size of lowest-level units in the National Longitudinal Study of Youth is 200-250 dwelling units.

${ }^{6}$ As the research leading to these aggregations were financed by a program on rural regions,
} 
we will consider a subsample of Langen's aggregations. We restrict the sample to aggregations with fewer than 4000 inhabitants in 1970, and exclude all tracts from the 1960 census that were split across municipalities in the years between 1960 and 1970. For the purpose of examining the effect of moving, we limit our sample to those aged 0-4 in the 1960 census, who we can expect to live with their parents at the time of the 1970 census.

\subsection{Outcome variables and observed family background}

We classify all children living in the same private household as siblings, excluding all institutional households. For parental classification, we use the recorded information on "adult responsibles" in the household. The "adult responsibles" are in the majority of cases biological parents, but to the extent that children live apart from their biological parents the head of the household and the spouse of the head are indicated as "adult responsibles" in the census. In 1960 only 1.5 per cent of our sample lived in a household without any biological parents, compared to 3.2 per cent in 1970 .

Our measure of adult educational attainment of our main sample is taken from the register of the level of education maintained by Statistics Norway (Vassenden 1995). This register provides a detailed code of the type of the highest completed education, the completion date and how many years of schooling the highest completed education corresponds to. For individuals with no recent education, their level of education as of the 1970 census is recorded.

Our measure of adult earnings is constructed from administrative data that are collected from tax returns and various government agencies. We use the 199095 observations of a category of earnings that is used to calculate accumulation of insurance benefits. This definition includes wages, income from self-employment, unemployment benefits and sick-leave payments, but excludes capital income, social assistance, pensions and other transfers. We inflate all numbers by the Consumer Price Index, and exclude all observations from before the completion of education or of less than NOK 10,000 at 1995 prices. We calculate the mean of the logarithm of these observations for each individual.

[Table 1 about here.]

the lists linking addresses to tracts in urban areas were not used. 
Whereas our measure of adult education is the natural one, choosing a measure of adult earnings is more controversial. We want to measure permanent labour earnings. Unemployment insurance and sickness benefits are included as these are conditional on previous employment and we do not want fluctuations due to transitory unemployment or sickness periods to affect our estimates. The parameters we estimate are only defined for those who actually participate in the labour market and we have no ambition of correcting for non-random participation. The earnings cutoff of 10,000 NOK per year is of course arbitrary, but we set this level to avoid measurement errors and transitory participation to affect the estimates. A recent study based on very similar data performed a test which shows that the brother correlation in earnings is not very sensitive to variations in the cutoff point (Björklund, Eriksson, Jäntti, Raaum, and Österbacka 2002).

Since there may be secular trends and life-cycle effects in our outcome measures, all the numbers we calculate in this paper are residuals from a regression on dummy variables indicating the year of birth (following Solon et al. 2000).

Table 1 provides summary statistics of our sample compared to the full population from the administrative data in 1995. In order to include a family in our sample, the family must include at least two children aged 5-14 at the time of the census. We restrict ourselves to the families with at least two brothers or two sisters. Since we restrict attention to families with at least two same-sex individuals in the relevant age-group, our estimating samples are smaller than the full population of the relevant age-group. Even so, it does not seem that the samples are much different from the full population in terms of observed characteristics. There is a limited increase in the average years of education from the older to the younger cohorts, and this increase is stronger for women. The variance of the years of educations decreases from the older to the younger cohorts. The same is true of annual earnings, but this may simply reflect that earnings are measured at two different stages of the life-cycle. Our samples are orders of magnitude larger than that of Solon et al. (2000), who use 687 individuals from 144 clusters to examine educational attainment, Page and Solon (2003) use 443 individuals from 120 clusters to examine male earnings.

The measure we have of the educational attainment of the parents of individuals from our main sample is different. From the 1970 census we have education recorded as years of schooling. The 1960 measure of education is a categorical 
classification. We could in principle use a set of dummy indicators to correct for parental education but this would identify the coefficients from those neighbourhoods with two or more parents with the same educational background, and the 1960 and 1970 measures would not be comparable. We have therefore transformed the categorical parental education codes into years of education. We use repeated observations of the same individuals to construct a mapping from the 1960 codes to years of schooling, and then apply this mapping to all parents, regardless of whether we have in fact repeated observations of this parent.

\subsection{Estimation}

Estimation of the covariance of some characteristic within a group is not a difficult problem. There are many ways to combine these within-group estimates, but note that observations here consist of pairs of siblings. A family of 2 siblings contributes one such pair, a family of 3 contributes 3 and so on: With $S$ siblings, there are $S(S-1) / 2$ unique pairs. Solon et al. (2000) provides (6) as an estimator of the covariance between siblings of a variable $y$ with $\mathrm{E}(y)=0$,

$$
\sum_{c=1}^{C} W_{c}\left\{\sum_{f=1}^{F_{c}} W_{c f}\left[\sum_{s \neq s^{\prime}} \frac{y_{c f s} y_{c f s^{\prime}}}{S_{c f}\left(S_{c f}-1\right) / 2}\right] / \sum_{f=1}^{F_{c}} W_{c f}\right\} / \sum_{c=1}^{C} W_{c} .
$$

Here $c$ denotes neighbourhood, $f$ denotes family and $s$ denotes sibling, the $W_{c}$ and $W_{c f}$ 's are weights and $S_{c f}$ is the number of siblings in family $f$ in neighbourhood c. Solon et al. considered four different weighting schemes. In practise, we have found the differences among estimates with different weighting schemes to be negligible, and all estimates in this paper gives all sibling-pairs and neighbourpairs equal weight regardless of whether they came from large or small families and neighbourhoods. To centre the observation around zero, we follow Solon et al. and first regress the variable in question on dummies for each year of birth.

The estimation of neighbourhood correlations is complicated by the fact that we want the correlation of one individual in a family with all other individuals except its siblings, so that the neighbourhood covariance is not contaminated by sibling correlations in small neighbourhoods. For a pair of families with $S_{c f}$ and $S_{c f^{\prime}}$ siblings there are $S_{c f} S_{c f^{\prime}}$ unique pairs, and if there are $F$ families in the neighbourhood, there are $F(F-1) / 2$ unique family pairs. Solon et al. provide 
an estimator of the neighbourhood correlations that is similar in spirit to (6),

$$
\sum_{c=1}^{C} W_{c}\left\{\sum_{f \neq f^{\prime}} W_{c f f^{\prime}}\left[\sum_{s=1}^{S_{c f}} \sum_{s^{\prime}=1}^{S_{c f^{\prime}}} \frac{y_{c f s} y_{c f^{\prime} s^{\prime}}}{S_{c f} S_{c f^{\prime}}}\right] / \sum_{f \neq f^{\prime}} W_{c f f^{\prime}}\right\} / \sum_{c=1}^{C} W_{c} .
$$

In order to adjust for the effect of observed family characteristics, we follow Solon et al. (2000) and regress $y_{c f s}$ on a vector of observed characteristics $\tilde{X}_{c f}$ and neighbourhood dummies. Subtracting the covariance of the predicted familyeffects from the total covariance (as indicated in (5)) and dividing by the total variance of $y_{c f s}$, we obtain neighbour correlations that are adjusted for observed family characteristics.

We have no analytical expression for the variance of these estimators. Solon et al. use balanced half-samples to take into account the complex sampling procedure of the PSID data. We have chosen a bootstrap procedure that resamples blocks of data and repeats all initial corrections for every resampled set of data. Since neighbourhoods may well be correlated in a spatial sense, we use municipalities as units of resampling for both the sibling and neighbour correlations. Since we have complete coverage of a whole economy that is spread over a relatively large geographical area, we believe that there is limited room for spatial correlation to bias the standard errors, and that our strategy of resampling on municipalities provides us conservatively large estimates of the standard errors. Calculation of the bootstraps are computationally expensive, and we have limited the number of replication to $250 .^{7}$

\section{Results}

In this section we first report the empirical sibling and neighbour correlations. Then we present our preferred estimates of the upper bounds of neighbourhood effects that accounts for sorting on observed family characteristics. Finally, we report family effects, net of the impact of siblings growing up in the same neighbourhoods. In all cases, we show the estimates by gender, sets of birth cohorts and adult outcome measure. Several robustness checks are performed to back our

\footnotetext{
${ }^{7}$ With 250 replications there is still some variation in the standard errors when starting at different random seeds, but this variation is much to small to influence inference in any important way (evidence available on request).
} 
interpretation of the numbers as reliable estimates of neighbourhood and family effects, including discussions of how regional differences and neighbourhood misclassification affect our estimated neighbour correlations. We close this section with a discussion of policy changes during the 1950s, '60s and '70s that are candidates for explaining our results.

\subsection{Sibling and neighbour correlations in education and earnings}

The sibling and neighbour correlations are shown in Table 2. The brother correlation in years of schooling is around 0.42 and somewhat higher, around 0.46, for sisters. These figures are surprisingly similar to those found for other countries. According to Solon (1999), sibling correlations in years of education in the United States are a little higher than 0.5. Table 2 also reveals that the genderspecific education correlation is fairly stable across cohorts, with a slightly higher correlation for the younger birth cohorts. Thus, the total impact of family and neighbourhood characteristics shared by siblings seems to be constant over time. The neighbour correlations in education are much lower. While the male correlation is higher among those born 1946-55, the gender difference is negligible in the younger cohorts. While Solon et al. (2000) report an unadjusted neighbour correlation of around 0.2 in the United States, neighbourhoods seem to be less important in Norway. ${ }^{8}$ Moreover, the impact of location during childhood seems to have fallen over time, since the neighbour correlation is considerably lower in the younger birth cohorts. It drops from 0.112 to 0.061 for males and from 0.103 to 0.065 for females.

[Table 2 about here.]

Correlations are considerably lower when we look at earnings. The sibling correlations in the range of $0.15-0.20$ are similar to figures found in previous studies. Björklund et al. (2002) find that brother correlations in Scandinavia are significantly lower than the typical $0.3-0.4$ found in recent US studies. In spite of the higher education correlation for sisters, we find that earnings are less

\footnotetext{
${ }^{8}$ Note, however, that the estimates of Solon et al. (2000) come from a much smaller sample, with standard errors around 0.05 .
} 
correlated among sisters than among brothers. ${ }^{9}$ The brother correlation drops from the oldest to the youngest cohorts, from 0.203 to 0.185 , while the earnings correlation for sisters increases from 0.148 to 0.165 .

The neighbour correlations in adult earnings are positive, and higher for neighbouring boys are higher than for girls. The higher male correlation is found in both cohorts. For the older birth cohorts, the correlation in adult earnings among neighbouring boys is 0.059 and 0.029 for girls. As for education, the male correlation is reduced by approximately one half from the 1946-55 to the 1956-65 cohorts and somewhat less for females.

To summarise, the correlations indicate that both families and neighbourhoods matter. Local childhood communities have become less important in explaining the overall variation in adult outcomes over time, and the gender difference has been reduced as well.

\subsection{Neighbourhood effects}

The neighbour correlations in Table 2 are upward biased measures of the true influence neighbourhoods have on individuals, due to sorting of families into communities. Resemblance in adult outcomes among persons who spent their childhoods in the same community may partly, or even completely, reflect that neighbouring children experience similar family environments. In Table 2 we also report adjusted neighbour correlations in years of schooling where we subtract the covariance in effects of observed family characteristics. ${ }^{10}$

When we partial out the effect of parental education the correlation drops considerably. Family structure characteristics are less important, the numbers are very similar to the unadjusted figures. When combining the two sets of family background variables available for both cohorts, the correlation drops considerably, from 0.112 to 0.049 for males and from 0.103 to 0.041 for females in the 1946-55 cohorts. The impact of the family background adjustment is similar for the 1956-65 cohorts. The neighbour correlations for males and females have become more similar over time. Parental income information is only available for the younger cohort and this adjustment reduces the correlation slightly.

\footnotetext{
${ }^{9}$ Bound, Griliches, and Hall (1986) finds that sisters are more similar than brothers, but they examine residuals from wage equations.

${ }^{10}$ To prevent family background coefficients from being affected by neighbourhood effects, these are estimated with neighbourhood dummies.
} 
In Table 2 we also report bounds on the neighbourhood effects on adult earnings adjusted for family background. After subtracting the contribution of parental education, we find that the neighbour correlations fall in both cohorts and for both men and women. As for education, family structure is less important. Including parental income among the family controls has a negative, but modest, effect on the correlations.

Several important conclusions can be drawn from the estimates in Table 2 . First, observed family sorting into neighbourhoods does not fully explain the resemblance in adult earnings among persons who grew up in the same neighbourhood. Second, neighbourhoods have become less important as determinants of adult earnings. This is consistent with, and presumably partly explained by, the declining effects of neighbourhoods on educational attainment. Third, childhood location seems to have stronger effects on adult earnings for males than for females. This gender difference in earnings correlations among neighbouring children is present for both cohorts. Finally, the family background adjustment wipes out the difference between earnings and schooling correlations. While the unadjusted neighbour correlations are much higher for education than earnings, they are strikingly similar after having adjusted for observed family sorting into neighbourhoods, especially for the younger cohorts.

One might ask what the correlations mean in terms of absolute size of neighbourhood effects. If we consider male earnings, we can use the upper bound and the variance from Table 1, and find that the standard deviation of the neighbourhood effects to be smaller than 0.124 and 0.086 for the older and younger cohorts respectively. ${ }^{11}$ Although the correlations may seem low, the variance is large enough that the bounds on neighbourhood effects are in no way negligible.

\subsection{Family effects}

Previous studies of sibling correlations do not disentangle family from neighbourhood effects. The only exception, to our knowledge, is Page and Solon (2003). Table 2 suggests that family background is by far more important than neighbourhoods, but the sibling correlations also include the effects of siblings growing up in the same neighbourhoods. In this section we tighten the bound on family

\footnotetext{
${ }^{11}$ The estimates of neighbour correlation are those adjusted for parental education and family structure. The bound is calculated as $\operatorname{sd}\left(\beta^{\prime} Z_{c}\right) \leq \operatorname{sd}\left(y_{c f s}\right) \sqrt{\operatorname{corr}_{a d j}\left(y_{c f s}, y_{c f^{\prime} s^{\prime}}\right)}$.
} 
effects using the method described in Section 2.

The lower bound on family effects on education is 0.366 for older males. In the younger cohorts, we find that at least 0.401 of the male variance in schooling is explained by factors, other than childhood location, which siblings share. The female estimates are 0.416 and 0.454 , respectively. Thus the lower bound on family effects has increased slightly for both men and women. ${ }^{12}$

Considering male earnings, the lower bound on family effects is very similar for the two cohorts, 0.156 among those born 1946-55 compared to 0.160 for those born ten years later. Consequently, weaker neighbourhood effects could potentially account for all of the decrease in brother correlations in Table 2.

For females, the lower bound on the family effects on adult earnings is actually increasing from 0.127 in the older cohorts compared to 0.152 in the younger. This suggests that the higher earnings correlation among brothers compared to sisters in the older cohorts is partly explained by larger neighbourhood effects on earnings for males. While family effects on educational attainment seem to be somewhat stronger for females than for males, the gender difference is smaller for earnings. The lower bound on family effects on earnings in the younger cohort is basically the same for both sexes.

Since it seems the impact of neighbourhoods seems to have declined, one might wonder why the sibling-correlation did not declined correspondingly. But decline a drop need not be a necessary corollary. If fewer families are financially constrained when making human investments, other mechanisms which tend to create homogeneous families may well become more important. For instance, if ability sorting into education is important, it may well be that poorer families, formerly restricted from investing in all of their promising children, can afford to send all of them on to higher education as the effective price of attendance drops.

\subsection{Robustness checks}

In this section we discuss whether the neighbour correlations, and particularly the drop over time, could reflect other mechanisms than declining neighbourhood effects. We first check whether the neighbourhood effects represent permanent regional effects rather than impact of childhood local community. Then we address

\footnotetext{
${ }^{12}$ All the bounds discussed in this section are based on the largest set of family background characteristics that is available for both the older and younger cohorts.
} 
the decline by discussing changes in neighbourhood boundaries, sorting, measurement error in permanent earnings and misclassification of childhood community as alternative explanations for why the upper bound on neighbourhood effects is reduced.

The neighbour correlations may reflect impact of regional characteristics rather than local effects. In other words, what we label neighbourhood effects may represent permanent differences between children growing up in different regions (e.g. urban vs non-urban areas). Moreover, in the case of adult earnings it may also reflect interaction of location preferences and regional price levels (Griliches 1979). It is well-documented that workers in urban areas in the US are paid a premium for living and working there. ${ }^{13}$ If resemblance in adult earnings among neighbouring children simply reflects the interaction between geographical location preferences and regional wage and price differences, heavily influenced by where they grew up, it is only weakly related to what people think of as neighbourhood effects on adult welfare. Since we neither have a model of geographical mobility, nor good regional wage and price indices, we perform a simply check where neighbour correlations are estimated within childhood county. We add 20 county dummies to birth year variables in the process of constructing the outcome measure, and we only predict family effects on within county variation. In this way we condition out all effects of adult location that are explained by the region in which the person spent his childhood and thereby all variation in neighbourhoods across counties. If the effects are associated with region rather than neighbourhood, or if location preferences explained the correlations, we would expect the neighbour correlations to vanish. Table 3 reports the sibling and neighbour correlations, estimated within childhood county. By comparing Table 2 and Table 3, we find that the brother and sister correlations in adult outcomes are basically unchanged.

[Table 3 about here.]

The neighbourhood effects on educational attainment drop significantly, but do not disappear. Considering schooling years of the oldest cohorts first, the

\footnotetext{
${ }^{13}$ Using our measure of earnings in a Mincer earnings equation including schooling, experience, experience squared, sex and regional dummies, the largest difference is between the counties Aust-Agder (with low earnings) and Akershus, a 0.125 log points difference.
} 
neighbour correlations are reduced by approximately 25 per cent when we estimate within regions. Adjusting for childhood county has no important impact on the younger cohorts, although the within-county estimates are lower for both men and women.

Earnings correlation estimates are more affected by the childhood-region adjustment. This is what we would expect if is driven by regional wage and price differentials, since these will partly be accounted by adult location being strongly affected by childhood region. Comparing Tables 2 and 3 we see that the neighbour correlations in earnings drop by about 50 per cent when we estimate within counties. We also report the family background adjusted estimates in Table 3 following the same procedure as in Table 2 . The adjustment does reduce the correlations, especially for females where the neighbour correlations in earnings end up below 0.01 . The lower effects of neighbourhoods in the younger cohorts remain for both males and females. It is important to emphasise that the within-county estimates neglect all the effects of variation in neighbourhoods between counties and this downward bias can be substantial. To summarise, neighbourhood effects remain positive and declining even if we estimate within counties.

The next check is on neighbourhood boundaries which changed from 1960 to 1970. However, neighbourhoods were more narrowly defined in 1970 and the average number of residents was lower than in 1960. As the 1970 classification represents smaller communities, one would expect the estimated correlations to increase rather than fall.

In the cohort comparison we measure income at different points of the life cycle. The two sets of cohorts are measured while 25-40 and 35-50 years of age respectively. Whereas we have preferred to use permanent earnings, the correlations will be biased downward by measurement error or transitory components in our measure of average earnings (Solon, Corcoran, Gordon, and Laren 1991). One might suggest that we have a more noisy earnings measure for the younger cohort, potentially explaining the drop in the neighbour correlation. But any important bias of this kind would also affect the sibling correlations. With a simple measurement error model, the estimated correlation is proportional to the correlation in permanent earnings. Assume that any difference between our observed earnings and permanent earnings is generated by the same model for siblings and neighbours. If the drop in the estimated neighbour correlation was 
generated by a different degree measurement error, we would expect a similar relative decline in the sibling correlations. The stability, and even slight increase for women, suggests that this bias is likely to be small.

We interpret the estimates as upper bounds on the neighbour effects and the true effects can be constant if sorting on unobserved family characteristics has decreased over time. We check this explanation by looking at how adult education is distributed within and between neighbourhoods over time, since we expect any trend in sorting on unobserved family background to be similar to the trend in sorting on observed characteristics. If sorting decreased from 1960 to 1970, one would expect the between-neighbourhood component of the total variance in adult education to fall. Table 4 shows the opposite. Consequently, weaker sorting leading to an upper bound which is closer to the true neighbourhood effect in the younger cohorts does not seem to be the explanation.

[Table 4 about here.]

Finally, community misclassification error may explain the drop in neighbourhood correlation if family mobility increased during the 1950s and throughout the 1960s. We only observe location at one point in time. Since families move, neighbourhood effects tend to be downward biased for both cohorts. On the other hand, families tend to move to similar neighbourhoods. A recent study for the United States (Kunz, Page, and Solon 2003) shows that one-year observation of location does not create a significant bias in the neighbourhood effects, but this conclusion may not be applicable to Norwegian data. This misclassification explanation cannot be checked for the full samples, as changing boundaries makes a substantial number of neighbourhoods incomparable over time. Using the subset of comparable geographical units described in Section 3.1, we estimate different correlations of those who stay in the same and those who move to a different neighbourhood during the 1970s. We limit ourselves to those aged 0-4 in 1960, because we want to follow children who can be expected to live with their parents ten years later. As we discussed in section 3.1, these tract-aggregates contain more individuals and they cover larger geographical areas than the original units.

[Table 5 about here.]

The first column in Table 5 reports the neighbour correlations for the 1956-60 cohorts, based on those individuals who spent at least some of their first five years 
in the aggregated tracts, but with the same definitions of neighbourhoods as in the previous tables. The second column is based on the aggregated tracts, using the same set of individuals. As expected, aggregation implies that correlations fall somewhat. Splitting stayers and movers in column three and four, all correlations are lower for movers than for stayers, suggesting that mobility does create a slight downward bias. For male earnings, the correlation among stayers is twice that of movers. Even if misclassification may have increased over time, the magnitude of the difference between stayers and movers is too small to provide an explanation for the drop in neighbour correlations over time.

Since changing neighbourhood boundaries, weaker sorting of families into neighbourhoods, measurement error in earnings or misclassification of neighbourhoods cannot explain the drop in neighbour correlations over time, we are fairly confident that the true impact of location during childhood has declined. Although attributing this change to public policies must be speculative, we want to point to some reforms and policy changes that we find likely to have played a role.

\subsection{Possible explanations of declining neighbourhood ef- fects}

Local government services have been an important component in the building of the Norwegian welfare state after the Second World War. In the late 1940s real per capita local government spending increased by an annual rate of 9 per cent, remaining at a high level of around 5 per cent during the next three decades (Borge and Rattsø 2002). As a consequence, local public spending as a percentage of GDP increased from 9 per cent in the late 1940s to around 16 per

cent in the 1970s. During the same period, the relative variation in spending across municipalities declined sharply. In the years before and after the Second World War, the tax base given by the local private income level largely explained the variation in spending across municipalities. Redistributive measures such as central government grants to municipalities were gradually introduced, and by 1980 the correlation between current per capita municipal spending and private income had changed from large and positive to negative. As far as neighbourhood institutions providing primary school and health care services are concerned, the first three decades after the Second World War were characterised by an over- 
all expansion and an equalisation of spending across municipalities (Falch and Tovmo 2003).

The school reforms implemented in the 1960s and 1970s are particularly interesting as possible explanations for the drop in neighbourhood effect for the cohorts growing up around 1960 and 1970. Norway experienced a sequence of school reforms during this period. The reform of the primary school system during the 1950s introduced a common curriculum in all communities, as well as access to the same number of teaching hours throughout the country. The comprehensive school reform of the 1960s increased the minimum level of schooling from 7 to 9 years, unified the education system and provided a common curriculum for all schools. In the 1970s regional colleges were established to enhance equality of opportunity in terms of transition to higher education for people growing up in all regions. The total number of students in higher education grew by 53 per cent between 1971 and 1981 (table 190, Statistics Norway 2001).

Probably the most extensive of the school reforms was the comprehensive school reform implemented between 1960 and 1970. The aims of the reform were stated explicitly in several governmental background papers. They were to raise the level of education, to smooth the transition into higher education and to enhance equality of opportunities across socio-economic and geographical backgrounds. It is expected that this reform reduced the effect of family background as well as neighbourhoods from 1960 to 1970. While most of the cohorts born between 1946-55 completed compulsory education before the reform, the 1956-65 cohorts went to the new comprehensive schools. Analyses of the participation rate to higher education for cohorts born from 1942-1970 show a strong degree of regional equalisation (Hægeland, Klette, and Salvanes 1999). The comprehensive school reform weakened the impact of socio-economic background on transition to higher education (Aakvik, Salvanes, and Vaage 2003).

Access to student grants and loans was expanded in the late 1960s and early 1970s. A grant for students older than 16 who lived more than $40 \mathrm{~km}$ away from their parents was introduced in 1968. Generally, from the age of 18 all students were entitled to a subsidised loan which covered living expenses. Tuition fees at Norwegian universities have been negligible. One motivation for the student grant and loan scheme introduced during the late 1960s was to promote equality of opportunity, such that educational qualifications could be attained independent 
of geographical location, age, gender, economic or social status. ${ }^{14}$

\section{Concluding Remarks}

Family background and childhood neighbourhood play an important role in explaining adult education and earnings. While most studies evaluating the combined effects of family and neighbourhoods are from the United States, we present evidence from a country with different labour market institutions, educational system and welfare policies. Census data from Norway enable us to construct neighbourhoods and use a detailed set of family background variables. We focus especially on whether the impacts of neighbourhoods and families have changed over time, estimating separate parameters for children born 1946-55 and those born ten years later. Our main results can be summarised as follows.

Neighbour correlations in years of schooling for the 1946-55 birth cohorts are 0.112 for boys and 0.103 for girls. The log earnings correlations are estimated to be 0.059 and 0.029 , respectively. Comparing the 1946-55 with the 1956-65 birth cohorts, we find a declining effect of neighbourhoods as the correlations are reduced by approximately one half.

Neighbour correlations are upward biased estimates of the influence of local childhood environments because similar families cluster in communities. We tighten the bound on the variance of neighbourhood effects by using data on observed family background. Adjusting for observed family background, the correlations drop considerably, for education down to 0.043 and 0.041 for the oldest boys and girls, respectively. Earnings correlations among neighbouring children born 1946-55 are reduced to 0.047 and 0.021 , for boys and girls respectively. In the younger cohorts, the neighbour correlations are approximately reduced by half.

We discuss whether the decline in neighbour correlation reflect changes in neighbourhood boundaries or reduced sorting of families into communities, and reject these explanations. Although higher geographical mobility among parents and measurement error in adult earnings for the younger cohorts may contribute to lower earnings correlations among neighbouring children over time, these

\footnotetext{
${ }^{14}$ This was later formulated in the first paragraph in "Lov om utdanningsstøtte til elever og studenter", law of 26.04.1985, no. 21.
} 
factors only explain a minor part.

The impact of families, net of neighbourhood effects shared by siblings, is found to be fairly stable across cohorts. For adult earnings we find adjusted brother correlations of 0.156 and 0.160 , for the older and younger cohorts respectively. The corresponding sister correlations are 0.127 and 0.152 , suggesting a convergence between sexes.

Families and neighbourhoods have weaker effects on adult outcomes in Norway than in the United States, adding to the evidence that intergenerational mobility is higher in the Scandinavian welfare states than in the United States (Björklund and Jäntti 1997). We offer no rigorous tests of why neighbourhoods explain a lower fraction of the variation in adult outcomes among the younger cohorts; however, we single out the expansion of local government services in general, and education reforms in particular, as important candidates. These policies were implicitly targeted to promote equality of opportunity. These policy reforms affected the post-war birth cohorts differently. In particular, those born after 1955 faced a more similar school system and lower costs of educational investment than those born during the previous decade.

\section{References}

Aakvik, A., Salvanes, K. G., and Vaage, K. (2003). 'Measuring heterogeneity in the returns to education in Norway using educational reforms', IZA Discussion Paper 815 .

Altonji, J. G. (1988). 'The effects of family background and school characteristics on education and labor market outcomes of relatives', mimeo, Northwestern University.

Björklund, A., Eriksson, T., Jäntti, M., Raaum, O., and Österbacka, E. (2002). 'Brother correlations in earnings in Denmark, Finland, Norway and Sweden compared to the United States', Journal of Population Economics, vol. 15, pp. $757-772$.

Björklund, A. and Jäntti, M. (1997). 'Intergenerational income mobility in Sweden compared to the United States', American Economic Review, vol. 87, pp. 1009-1018. 
Black, S. E. (1999). 'Do better schools matter? Parental valuation of elementary education', Quarterly Journal of Economics, vol. 114, pp. 577-599.

Borge, L.-E. and Rattsø, J. (2002). 'Spending growth with vertical fiscal imbalance: Norway 1880-1990', Economics and Politics, vol. 14, pp. 351-373.

Bound, J., Griliches, Z., and Hall, B. H. (1986). 'Wages, schooling and IQ of brothers and sisters: Do the family factors differ?', International Economic Review, vol. 27, pp. 77-105.

Bureau of the Census (1994). Geographic Areas Reference Manual, U.S. Dept. of Commerce, Economics and Statistics Administration, Bureau of the Census, Washington, D.C.

Byfuglien, J. and Langen, O. R. (1983). 'Grunnkretser, tettsteder og menigheter: Dokumentasjon 1980', Rapport 13/83, Statistisk Sentralbyrå.

Conley, T. G. and Topa, G. (2002). 'Socio-economic distance and spatial patterns in unemployment', Journal of Applied Econometrics, vol. 17, pp. 303-327.

Dearden, L., Machin, S., and Reed, H. (1997). 'Intergenerational mobility in Britain', The Economic Journal, vol. 107, pp. 47-66.

Durlauf, S. N. (2001). 'The memberships theory of poverty: The role of group affiliations in determining socioeconomic outcomes', in 'Understanding Poverty', (eds. S. H. Danziger and R. H. Haveman), chap. 11, Harvard University Press, pp. 392-416.

Edin, P.-A., Fredriksson, P., and Åslund, O. (2003). 'Ethnic enclaves and the economic success of immigrants - evidence from a natural experiment', Quarterly Journal of Economics, vol. 118, pp. 329-357.

Ermisch, J. and Francesconi, M. (2001). 'Family matters: Impacts of family background on educational attainments', Economica, vol. 68, pp. 137-156.

Falch, T. and Tovmo, P. (2003). 'Norwegian local public finance in the 1930s', European Review of Economic History, vol. 7, pp. 127-154. 
Gibbons, S. (2002). 'Neighbourhood effects on educational achievement: Evidence from the Census and National Child Development Study', mimeo, Centre for Economics and Education.

Gibbons, S. (2003). 'Paying for good neighbours: Estimating the value of an educated community', Urban Studies, vol. 40, pp. 809-833.

Gibbons, S. and Machin, S. (2002). 'Valuing english primary schools', forthcoming, Journal of Urban Economics.

Ginther, D., Haveman, R., and Wolfe, B. (2000). 'Neighborhood attributes as determinants of children's outcomes: How robust are the relationships?', Journal of Human Resources, vol. 35, pp. 603-42.

Griliches, Z. (1979). 'Sibling models and data in economics: Beginnings of a survey', Journal of Political Economy, vol. 87, pp. S37-64.

Hægeland, T., Klette, T. J., and Salvanes, K. G. (1999). 'Declining returns to education in Norway? comparing estimates across cohorts, sectors and time', Scandinavian Journal of Economics, vol. 101, pp. 555-576.

Jargowsky, P. A. (1996). 'Take the money and run: Economic segregation in U.S. metropolitan areas', American Sociological Review, vol. 61, pp. 984-998.

Katz, L. F., Kling, J. R., and Liebman, J. B. (2001). 'Moving to opportunity in Boston: Early results of a randomized mobility experiment', Quarterly Journal of Economics, vol. 116, pp. 607-654.

Kremer, M. (1997). 'How much does sorting increase inequality?', Quarterly Journal of Economics, vol. 112, pp. 115-139.

Kunz, J., Page, M. E., and Solon, G. (2003). 'Are point-in-time measures of neighborhood characteristics useful proxies for children's long-run neighborhood environment?', Economics Letters, vol. 79, pp. 231-237.

Langen, O. R. (1975). 'Folketellingskretsene i Norge 1960 og 1970: Sammenliknbare kretsenheter.', mimeo Geografisk institutt, Norges Handelshøyskole og Universitetet i Bergen, geografiske studier av utkantstrøk i Norge, Arbeidsrapport nr. 6 . 
Møen, J., Salvanes, K. G., and Sørensen, E. Ø. (2003). 'Documentation of the linked employer-employee dataset at Norwegian School of Economics', mimeo, Norwegian School of Economics.

Oreopoulos, P. (2003). 'The long-run consequences of living in a poor neighborhood', forthcoming, Quarterly Journal of Economics.

Page, M. E. and Solon, G. (2003). 'Correlations between brothers and neighboring boys in their adult earnings: The importance of being urban', forthcoming, Journal of Labor Economics.

Solon, G. (1999). 'Intergenerational mobility in the labor market', in 'Handbook of Labor Economics', (eds. O. Ashenfelter and D. Card), vol. 3a, chap. 29, Amsterdam: North-Holland, pp. 1761-1800.

Solon, G., Corcoran, M., Gordon, R., and Laren, D. (1991). 'A longitudinal analysis of sibling correlations in economic status', Journal of Human Resources, vol. 26 , pp. 509-534.

Solon, G., Page, M. E., and Duncan, G. J. (2000). 'Correlation between neighboring children in their subsequent educational attainment', Review of Economics and Statistics, vol. 82, pp. 383-392.

Statistics Norway (2001). Statistical Yearbook 2001, Statistics Norway.

Topa, G. (2001). 'Social interactions, local spillovers and unemployment', Review of Economic Studies, vol. 68, pp. 261-295.

Vassenden, E. (1995). 'The register of the level of education: a product of the integration of other registers, census and surveys', Statistisk sentralbyrå, Notater $95 / 4$.

Vassenden, K. (1987). 'Folke- og boligtellingene 1960, 1970 og 1980: Dokumentasjon av de sammenlignbare filene', Statistisk sentralbyrå, Notater 87/2. 
Table 1. Comparison of samples with population

\begin{tabular}{|c|c|c|c|c|c|c|}
\hline & \multicolumn{3}{|c|}{ 1946-55 cohorts } & \multicolumn{3}{|c|}{ 1956-65 cohorts } \\
\hline & earnings & education & pop. & earnings & education & pop. \\
\hline \multicolumn{7}{|l|}{ Male: } \\
\hline mean age & 44.48 & 44.48 & 44.56 & 34.38 & 34.39 & 34.41 \\
\hline mean education (years) & 11.53 & 11.45 & 11.58 & 11.89 & 11.86 & 11.91 \\
\hline (standard deviation) & 2.89 & 2.92 & 2.93 & 2.30 & 2.39 & 2.30 \\
\hline mean log av earnings 1995 & 12.31 & 12.30 & 12.31 & 12.19 & 12.20 & 12.20 \\
\hline (standard deviation) & 0.57 & 0.58 & 0.58 & 0.55 & 0.55 & 0.55 \\
\hline share full time working 1995 & 0.735 & 0.704 & 0.714 & 0.733 & 0.720 & 0.726 \\
\hline share unemployed 1995 & 0.075 & 0.074 & 0.072 & 0.108 & 0.108 & 0.107 \\
\hline number of people & 106287 & 113739 & 290345 & 122413 & 125436 & 297734 \\
\hline \multicolumn{7}{|l|}{ Female: } \\
\hline mean age & 44.49 & 44.48 & 44.55 & 34.40 & 34.41 & 34.47 \\
\hline mean education (years) & 11.00 & 10.88 & 10.99 & 11.84 & 11.74 & 11.82 \\
\hline (standard deviation) & 2.60 & 2.60 & 2.60 & 2.29 & 2.27 & 2.28 \\
\hline mean log av earnings 1995 & 11.77 & 11.76 & 11.77 & 11.67 & 11.66 & 11.68 \\
\hline (standard deviation) & 0.62 & 0.63 & 0.63 & 0.66 & 0.66 & 0.66 \\
\hline share full time working 1995 & 0.460 & 0.429 & 0.430 & 0.436 & 0.408 & 0.412 \\
\hline share unemployed 1995 & 0.064 & 0.064 & 0.063 & 0.102 & 0.103 & 0.100 \\
\hline number of people & 92581 & 103109 & 278381 & 103308 & 114549 & 286074 \\
\hline
\end{tabular}

Note: The table compares the samples that remains after linking the administrative files with the census files and restricting the sample to tracts with at least two families of two individuals with non-missing observations. 
Table 2. Correlation in education and adult earnings among siblings and neighbouring children.

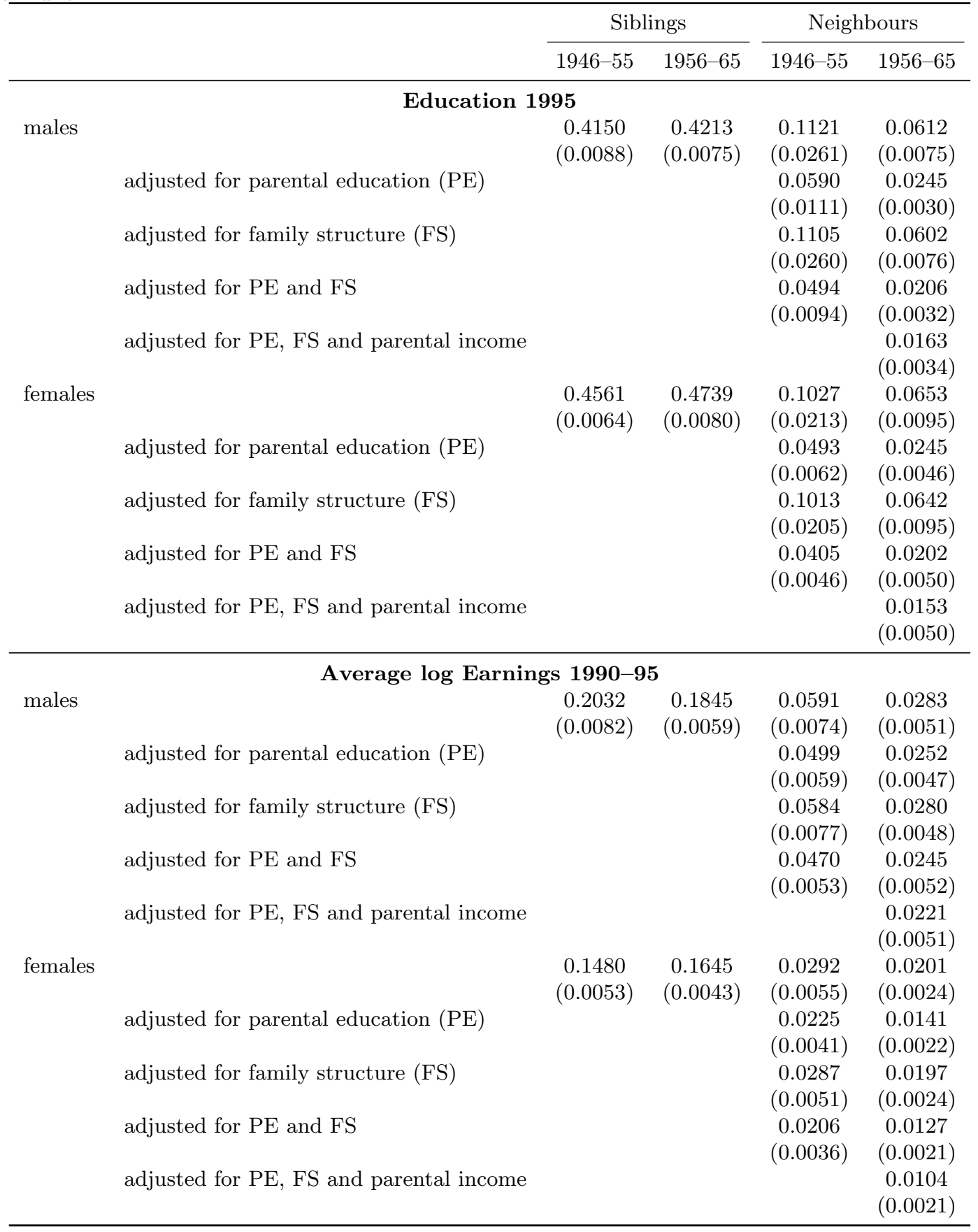

Note: Estimated on the full population of those aged between 5-15 in the year of the census in families with at least 2 children in this age span, and in neighbourhoods with at least two such families. Correlations in education based on 1995 data, the earnings measure is the mean of logarithm of earnings 1990-95, dropping those years before completion of education or with less than NOK (1998) 10,000 in earnings.

The variables for parental education include a 4th degree polynomial in mother's and father's education and a first degree interaction term and dummies for whether any of these are missing. The family structure variables include indicators for whether parents are currently divorced, separated, presence of a step-parent or non-biological parents, single parents and size of the household. Parental income consists of the logarithm of the income of the responsible adults and indicators for whether any of these are missing. 
Table 3. Correlation in education and adult earnings among siblings and neighbouring children. Within regions.

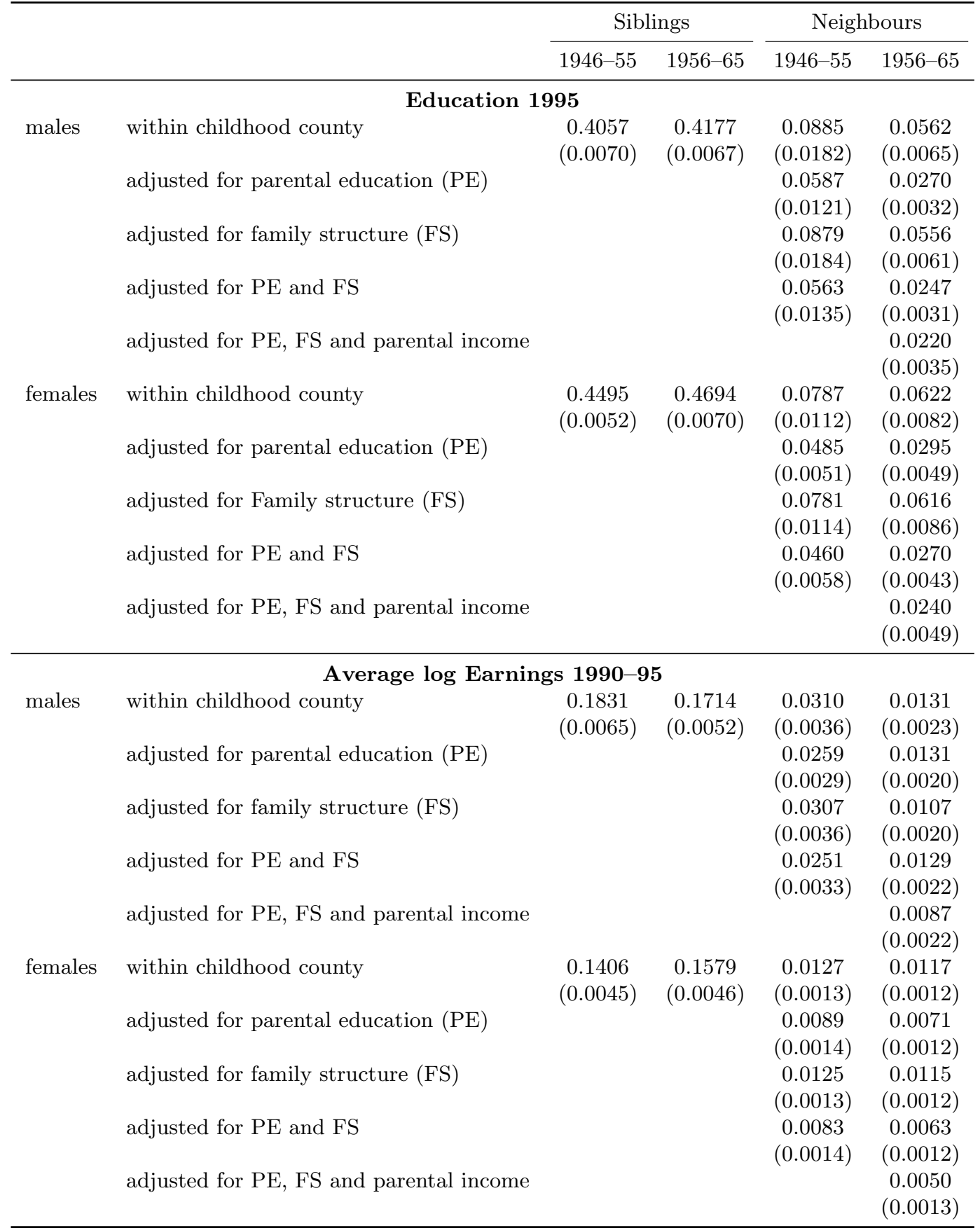

Note: Estimated on the full population of those aged between 5-15 in the year of the census in families with at least 2 children in this age span, and in neighbourhoods with at least two such families. Correlations in education based on 1995 data, the earnings measure is the mean of logarithm of earnings 1990-95, dropping those years before completion of education or with less than NOK (1998) 10,000 in earnings. Both the outcome variable and the observed family characteristics have their county mean subtracted.

The variables for parental education include a 4th degree polynomial in mother's and father's education and a first degree interaction term and dummies for whether any of these are missing. The family structure variables include indicators for whether parents are currently divorced, separated, presence of a step-parent or non-biological parents, single parents and size of the household. Parental income consists of the logarithm of the income of the responsible adults and indicators for whether any of these are missing. 
Table 4. Degree of neighbourhood sorting

\begin{tabular}{lcrrrr}
\hline & \multicolumn{2}{c}{ female education } & & \multicolumn{2}{c}{ male education } \\
\cline { 2 - 3 } \cline { 5 - 6 } & 1960 & 1970 & & 1960 & 1970 \\
\hline mean & 8.008 & 8.627 & & 8.641 & 0.932 \\
$\hat{\sigma}_{u}$ & 0.557 & 0.900 & & 0.935 & 1.269 \\
$\hat{\sigma}_{\epsilon}$ & 1.578 & 1.194 & & 2.274 & 2.516 \\
$\hat{\rho}=\hat{\sigma}_{u}^{2} /\left(\hat{\sigma}_{u}^{2}+\hat{\sigma}_{\epsilon}^{2}\right)$ & 0.104 & 0.177 & & 0.145 & 0.203 \\
\hline
\end{tabular}

Note: Decomposition of the variance of adult educational attainment at the time of the censuses. Estimates from the regression $E_{i c}=\bar{E}+u_{c}+\epsilon_{i c}$ (with neighbourhood fixed effects). Calculated on the population of individuals aged $30-50$ at the time of the censuses. 
Table 5. Stayers and movers

\begin{tabular}{|c|c|c|c|c|c|}
\hline & & all (tracts) & all (aggregations) & stayers & movers \\
\hline \multicolumn{6}{|l|}{ education } \\
\hline & male & $\begin{array}{c}0.0593 \\
(0.0074)\end{array}$ & $\begin{array}{c}0.0444 \\
(0.0124)\end{array}$ & $\begin{array}{c}0.0482 \\
(0.0130)\end{array}$ & $\begin{array}{c}0.0363 \\
(0.0119)\end{array}$ \\
\hline & female & $\begin{array}{c}0.0589 \\
(0.0102)\end{array}$ & $\begin{array}{c}0.0400 \\
(0.0156)\end{array}$ & $\begin{array}{c}0.0418 \\
(0.0160)\end{array}$ & $\begin{array}{c}0.0311 \\
(0.0131)\end{array}$ \\
\hline \multicolumn{6}{|l|}{ earnings } \\
\hline & male & $\begin{array}{c}0.0334 \\
(0.0031)\end{array}$ & $\begin{array}{c}0.0296 \\
(0.0056)\end{array}$ & $\begin{array}{c}0.0377 \\
(0.0057)\end{array}$ & $\begin{array}{c}0.0173 \\
(0.0052)\end{array}$ \\
\hline & female & $\begin{array}{c}0.0201 \\
(0.0023)\end{array}$ & $\begin{array}{c}0.0155 \\
(0.0035)\end{array}$ & $\begin{array}{c}0.0164 \\
(0.0035)\end{array}$ & $\begin{array}{c}0.0114 \\
(0.0028)\end{array}$ \\
\hline
\end{tabular}

Note: Neighbour correlations for sample of stayers and movers. The sample includes those aged $0-5$ in 1960 and with mothers living in one of 4969 tract aggregations with fewer than 4000 inhibitants and not containing 1960 tracts that were split among several tracts in the 1970 census. The first column summarizes this sample at the lower tract level, stayers and movers inclusive. The group "stayers" lived in the same tract aggregation in 1970 as in 1960, while the "movers" (27.5 per cent of the sample) had moved to some different tract aggregation. 


\section{IZA Discussion Papers}

\begin{tabular}{|c|c|c|c|c|}
\hline No. & Author(s) & Title & Area & Date \\
\hline 938 & $\begin{array}{l}\text { D. Del Boca } \\
\text { A. Venturini }\end{array}$ & Italian Migration & 1 & $11 / 03$ \\
\hline 939 & E. Toulemonde & $\begin{array}{l}\text { Acquisition of Skills, Education Subsidies, and } \\
\text { Agglomeration of Firms }\end{array}$ & 2 & $11 / 03$ \\
\hline 940 & $\begin{array}{l}\text { A. Constant } \\
\text { Y. Shachmurove } \\
\text { K. F. Zimmermann }\end{array}$ & $\begin{array}{l}\text { What Makes an Entrepreneur and Does It Pay? } \\
\text { Native Men, Turks, and Other Migrants in } \\
\text { Germany }\end{array}$ & 1 & $11 / 03$ \\
\hline 941 & $\begin{array}{l}\text { R. V. Burkhauser } \\
\text { J. S. Butler } \\
\text { G. Gumus }\end{array}$ & $\begin{array}{l}\text { Option Value and Dynamic Programming Model } \\
\text { Estimates of Social Security Disability Insurance } \\
\text { Application Timing }\end{array}$ & 6 & $11 / 03$ \\
\hline 942 & $\begin{array}{l}\text { R. V. Burkhauser } \\
\text { J. S. Butler } \\
\text { G. Gumus }\end{array}$ & $\begin{array}{l}\text { Dynamic Modeling of the SSDI Application } \\
\text { Timing Decision: The Importance of Policy } \\
\text { Variables }\end{array}$ & 6 & $11 / 03$ \\
\hline 943 & $\begin{array}{l}\text { J. T. Addison } \\
\text { P. Teixeira }\end{array}$ & $\begin{array}{l}\text { What Have We Learned About the Employment } \\
\text { Effects of Severance Pay? Further Iterations of } \\
\text { Lazear et al. }\end{array}$ & 3 & $11 / 03$ \\
\hline 944 & $\begin{array}{l}\text { H. Görg } \\
\text { D. Greenaway }\end{array}$ & $\begin{array}{l}\text { Much Ado About Nothing? Do Domestic Firms } \\
\text { Really Benefit from Foreign Direct Investment? }\end{array}$ & 2 & $11 / 03$ \\
\hline 945 & $\begin{array}{l}\text { R. Schöb } \\
\text { D. E. Wildasin }\end{array}$ & $\begin{array}{l}\text { Economic Integration and Labor Market } \\
\text { Institutions: Worker Mobility, Earnings Risk, and } \\
\text { Contract Structure }\end{array}$ & 2 & $12 / 03$ \\
\hline 946 & M. Leonardi & $\begin{array}{l}\text { Earnings Instability of Job Stayers and Job } \\
\text { Changers }\end{array}$ & 1 & $12 / 03$ \\
\hline 947 & U. Sunde & $\begin{array}{l}\text { Potential, Prizes and Performance: Testing } \\
\text { Tournament Theory with Professional Tennis } \\
\text { Data }\end{array}$ & 7 & $12 / 03$ \\
\hline 948 & $\begin{array}{l}\text { A. Kugler } \\
\text { G. Pica }\end{array}$ & $\begin{array}{l}\text { Effects of Employment Protection and Product } \\
\text { Market Regulations on the Italian Labor Market }\end{array}$ & 6 & $12 / 03$ \\
\hline 949 & C. J. Flinn & $\begin{array}{l}\text { Minimum Wage Effects on Labor Market } \\
\text { Outcomes under Search with Bargaining }\end{array}$ & 6 & $12 / 03$ \\
\hline 950 & $\begin{array}{l}\text { P. Garibaldi } \\
\text { E. Wasmer }\end{array}$ & $\begin{array}{l}\text { Equilibrium Employment in a Model of Imperfect } \\
\text { Labor Markets }\end{array}$ & 1 & $12 / 03$ \\
\hline 951 & $\begin{array}{l}\text { P. Garibaldi } \\
\text { E. Wasmer }\end{array}$ & $\begin{array}{l}\text { Raising Female Employment: Reflexions and } \\
\text { Policy Tools }\end{array}$ & 5 & $12 / 03$ \\
\hline 952 & $\begin{array}{l}\text { O. Raaum } \\
\text { K. G. Salvanes } \\
\text { E. Ø. Sørensen }\end{array}$ & The Neighbourhood Is Not What It Used to Be & 3 & $12 / 03$ \\
\hline
\end{tabular}

An updated list of IZA Discussion Papers is available on the center's homepage www.iza.org. 